\title{
"The Impact of Vehicular Explosion on Annual Means Temperature in the Urban Environment- A Case Study of Kolkata.
}

\author{
Dr. Alpana Ray \\ Assistant Professor in Geography Prasanta Chandra Mahalonobis College Baranagar, Kolkata, West Bengal, \\ India
}

\begin{abstract}
Transport sector is one of the biggest contributors to changing climate in cities around the world. Prior studies on many urban locations both in Asia as well as EU have reported that there is a strong positive relation between number of vehicles and temperature change in a given location. However, no research has been reported investigating this topic in Kolkata. This paper investigates the relation between the growth of personal vehicles (cars and two wheelers) and change in annual mean temperatures in the city of Kolkata. I have created a time series database collating secondary data obtained from multiple sources for the period between 1984 and 2010 and used regression analysis technique to test the relationship between growth of personal vehicles and change in mean annual temperature. The analysis shows that mean minimum temperature in Kolkata has increased from $21.8^{\circ} \mathrm{C}(1984)$ to $23^{\circ} \mathrm{C}(2010)$ - an increase of $1.2^{\circ} \mathrm{C}$ in the last twenty five years. There is a clear evidence of warming at night with increase of mean minimum temperature. The regression results suggest a positive and significant relationship between growth of personal vehicles and change in mean annual temperature and the trend line has a positive $r$ value of +0.52 . Understandably, the emissions of carbon monoxide, lead, sulphur oxides, nitrogen oxides, etc. from vehicles contribute to this increase. The paper concludes by suggesting some remedial measures emphasizing on the role of public transport to mitigate climate change through the reduction of green house gas emissions.
\end{abstract}

Key Words: climate change, green house gas emission, regression analysis, urbanization, vehicular explosion.

\section{Introduction}

Cities as home to over half the world's population are at the forefront of the challenge of climate change. Climate Change is potentially one of the most serious environmental threats facing the world today. Fourth Assessment Report (AR4) of the Intergovernmental Panel on Climate Change (IPCC, 2007a) also concluded that there is a greater than 90 percent chance that the average global temperature increases over the last century and one of the important factors of increase of global temperature is the increase of greenhouse gases mainly from transport sector [1]. Cities are key hubs of the transportation sector. The personal motor car is the second biggest contributor to greenhouse gas emissions in the transport sector (behind road freight) and it is also one of the major contributor to climatic change in Urban India [2]. Prior studies on many urban locations both in Asia as well as EU have reported that there is a strong positive relation between number of vehicles and temperature change in a given location. D. Banister (2010), D. Das, A. Sharfouddin, , S. Datta, (2009), A. Dhored, A.S Gadgil.(2009), K.M.Ghose, (2009), K. Rupa Kumar, \& L.S Hingane,(1988), R. Hickman, R.Ashiru, J Cook, D.S Lere, A. Sterke (2010), L. Chapmar (2007) have attempted to quantify the effect of transportation on climate change in different cities in the World. However, no research has been reported investigating this topic in Kolkata, which is provides an ideal location for such a study because of its unique, complex urban history, uncontrolled haphazard urbanization, vehicular explosion mainly two wheelers and personalized cars in the last fifty years. So this paper investigates the relation between the growth of personal vehicles (cars and two wheelers) and change in annual mean temperatures in the city of Kolkata. The broad emphasis of this paper is to examine the study of vehicular pollution emanating from the interaction of urbanization and vehicular explosion especially role of personal vehicles two wheelers and personalized cars in the city of Kolkata in India and its impact in the possible micro climatic change mainly the change in mean annual temperature in the city.

\section{Methodology}

A time series database has been created collating secondary data obtained from multiple sources for the period between 1984 and 2010 and these are used for regression analysis technique to test the relationship between growth of personal vehicles and change in mean annual temperature. Four types of parameters have 
been chosen-(total vehicular population, change in total vehicular population and change in number of personal vehicles, change in mean minimum temperature and maximum temperature) to study the relationship between number of vehicle increase and change in mean minimum or maximum temperature for Kolkata between 19842010 .

The analytical part of the research is the analysis and perception of research problem based on the compilation of various secondary data from respective offices, collection of archival materials, downloaded information through websites, the suggestions and recommendations made by the Directors of different Government organizations, Scientists and also analysis of primary data on from field visits to fulfill the objective.

\section{Location Of The Study Area- Kolkata}

The present research is confined within Kolkata Municipal Corporation (KMC) boundary, which lies between $22^{\circ} 28^{\prime} \mathrm{N}$ to $22^{\circ} 37^{\prime} 30^{\prime \prime} \mathrm{N}$, and $88^{\circ} 15^{\prime} \mathrm{E}$ to $88^{\circ} 30^{\prime} \mathrm{E}$ (Fig.1a). The Kolkata Municipal Corporation spreads over an area of $187.33 \mathrm{sq} \mathrm{km}$ with a population of 4.48 million according to 2011Census Report and one of the largest cities in India. One of the major contributing factors to the growth of Kolkata City is its everincreasing population (Fig.1b)

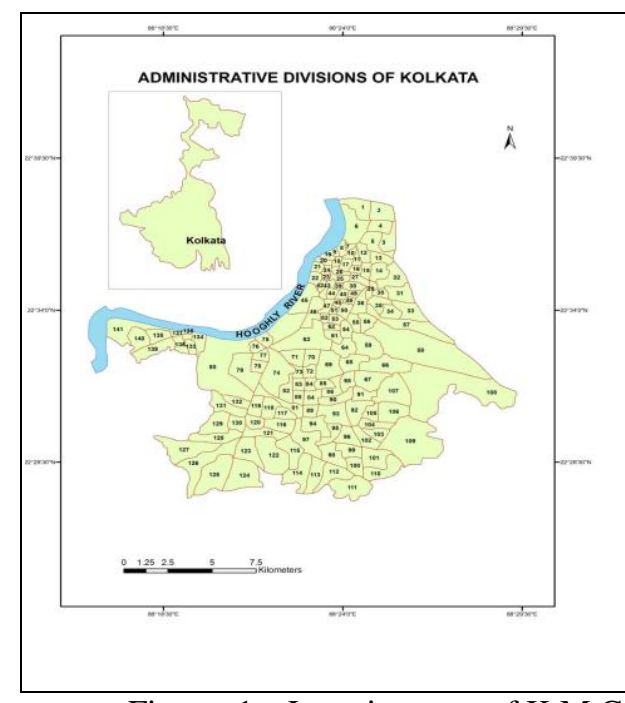

Figure: 1a :Location map of K.M.C

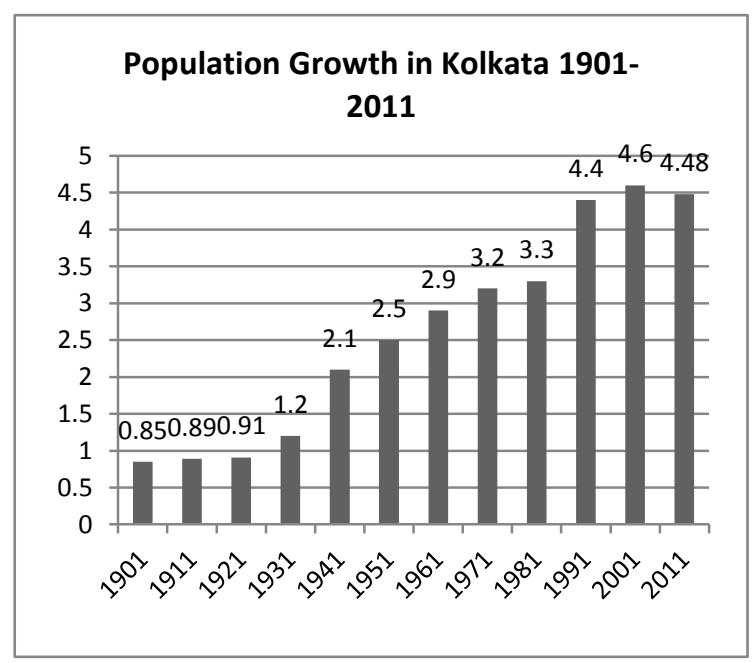

Figure:1b: Population Growth In K.M.C

(Source : Census of India :2011)

\section{Growth Of Transportation System In Kolkata}

Kolkata is one of the largest cities in India. The former capital of British India, Kolkata today forms the commercial and industrial hub of eastern India. Kolkata has an extensive local transport system. In the study period i.e 1985 to 2010 twenty five years, the total vehicular population has increased five times from 2 lakh 61 thousand to 10 lakh 62 thousand in Kolkata City (Fig.2). The share of personal vehicles has increased to 83\%, in which the share of cars is $44 \%$ and motor bikes are $39 \%$ in total number of vehicles.

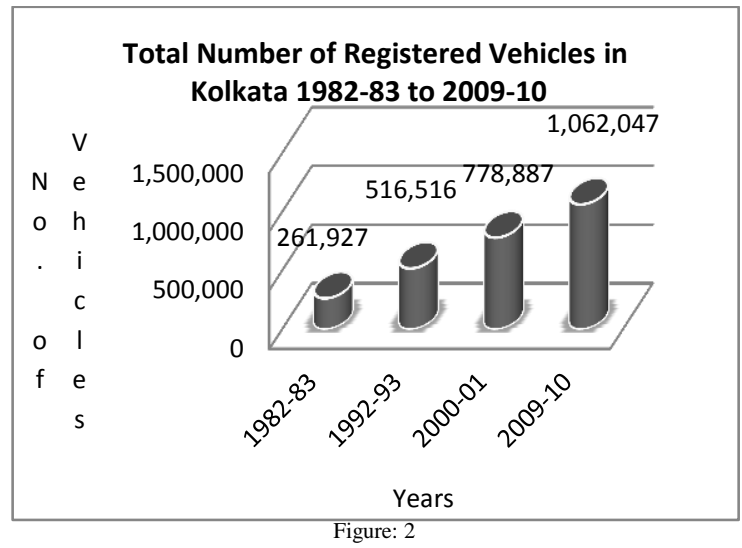


Annual average growth rate for five years of all vehicular population show that only personal car population has an increasing trend. In 1989-90 to 1994-95 the growth rate was 4.04\%, 95 to 2000 it was $4.29 \%$ and $2000-2005$ it was $5.41 \%$. All the vehicles including personal and commercial vehicles have positive growth rates except five year annual growth rate(-3.32\%) of buses in 1995-2000 but the trend is decreasing. So, all these show that number of personal cars are increasing hand in hand with urbanization at a faster rate in Kolkata city though roads are not sufficiently increasing (Fig.3). It results in expanding traffic congestion on roads, delay of travel, air pollution in the city and lastly climate change.

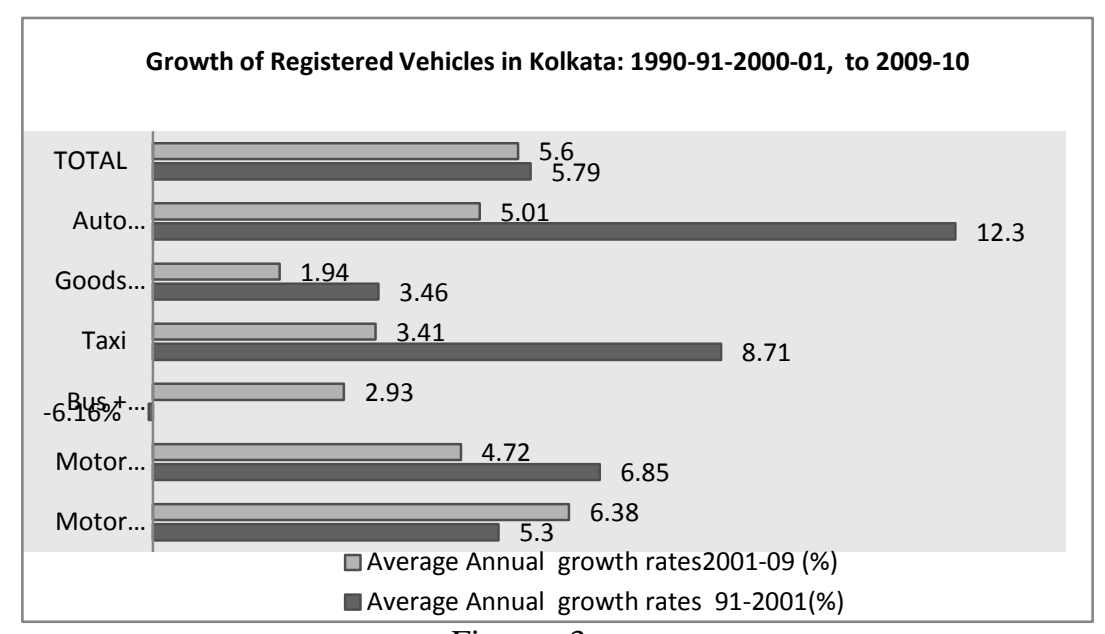

Figure : 3

Table $: 1$

\begin{tabular}{|l|l|l|l|l|}
\hline \multicolumn{5}{|l|}{ 5 Year Annual Average Growth rates (\%) in KolkataCity } \\
\hline Vehicle Type & $1989-1994$ & $1995-2000$ & $2001-2005$ & $2005-2010$ \\
\hline Goods Vehicle & 2.30 & 10.68 & 2.00 & -17.32 \\
\hline Motor Car \& jeep & 4.04 & 4.29 & 5.41 & -15.86 \\
\hline Motor Cycle \& Scooter & 6.86 & 5.64 & 4.56 & -9.15 \\
\hline Taxi \& Carriage & 4.75 & 7.69 & 4.27 & -2.58 \\
\hline Auto Rickshaw & 20.43 & 8.17 & 9.5 & 1.55 \\
\hline Mini Bus & 2.03 & -3.32 & 3.23 & 22.68 \\
\hline Tractor/Trailer & 0.45 & 0.98 & 0.3 & -17.24 \\
\hline
\end{tabular}

Source : Annual Report -West Bengal Transport Department

Even the 5 yr Annual Growth rates of different vehicles between 1989 to 2005 points out( TABLE :1) only car population has an increasing trend in Kolkata in all years that's 4.04\% in 1989-94, 4.29\% in 1995-2000 and $5.41 \%$ in 2001-2005. Here we do not consider the data of 2005-2010 as in this period in Kolkata as number of vehicles have been declined due to phasing out older vehicles.

Kolkata City always has highest percentage of personal vehicles than that of commercial vehicles. In 1984-85, data shows that the share of personal vehicles was 78\% amongst which $48 \%$ four wheelers and $30 \%$ two wheelers and the rest (i.e 22\%) occupied by commercial vehicles namely auto rickshaws, buses and taxis (Fig. 4a). After ten years, i.e in 1995, the share of personal vehicles rose to $81 \%$. The most interesting is that the share of four wheelers (cars and jeep) decreased from $48 \%$ to $37 \%$ and share of two wheelers increased from $30 \%$ to $44 \%$. It was mainly due to better conditions of roads and demolition of tramways in many areas of Kolkata city in present era. In 2010, the contribution of personal vehicles is $83 \%$ and $17 \%$ is occupied by commercial vehicles (Figure.4b). 


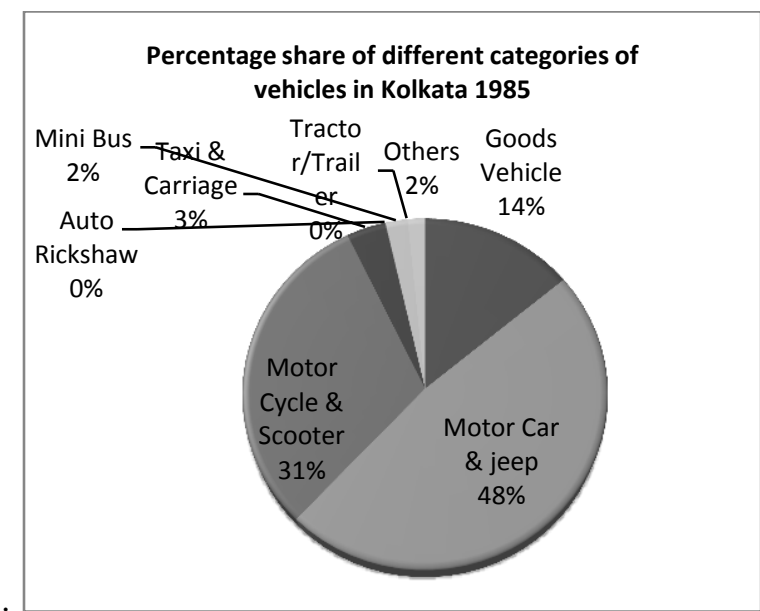

Figure: $4 \mathrm{a}$

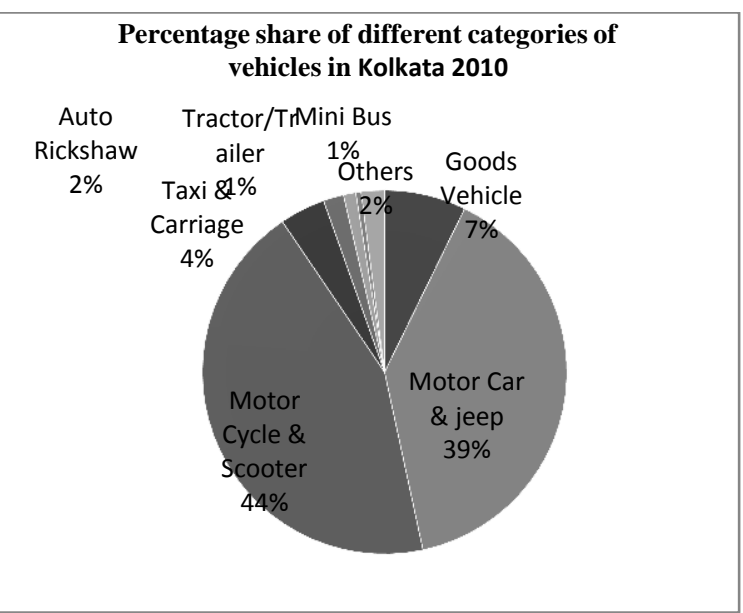

Figure: $4 \mathrm{~b}$

The role of public transport mainly buses and trams were important in Kolkata in early days as it was cheaper and more efficient than those of personal vehicles. The percentage share of buses increased from $1.96 \%$ in $1984-85$ to $2.42 \%$ in 1995 but after that the share declined to about $1.1 \%$ in 2008 and $1 \%$ in 2010 .The modal split shows that buses carry four times passengers average weekly (78.80 lakhs, 2005) in comparison to personal cars and two wheelers (19.46Lakh, 2005). But here has been a sharp decline in the percentage share of buses from $2.27 \%$ to $1.1 \%$ in the vehicular population in Kolkata city [10]. It is regrettable that public transport systems are neglected and allowed to decline due to uneconomic fares and outdated technologies. But the percentage share of auto and taxis both have increased to greater extent in 2010 than 1984-85 (auto .06\% in 1985 to $4.32 \%$ in 2010; taxi $3.52 \%$ in 1985 to $6.8 \%$ in 2010. But the growth of auto taxis and buses are all negligible as compared to the growth of personal vehicles in the city and all these matters have led to air pollution problem and climate change in long run.

Among the total vehicular population personal vehicles (two wheelers and four wheelers) are always highest in Kolkata city. They have positive growth throughout the study period and all the years have excess number of car and motor bikes population. In 1991-92 excess number of car population was lowest i.e only 931 and 2002-03 and 2006-07 the number of cars increased 20,000 annually (Fig.5a). In 1985-86 motor bikes increased to about 30,000 annually which was the highest among the excess number of motor vehicles in Kolkata city and was 2.5 times more than that car population. The study shows that the excess number of motorbikes was more than the excess number of car population in the early 80's and 90's in Kolkata city but after 2000 the picture was reverse. The total no of car population was ahead of motor bikes population (Fig. $5 \mathrm{~d})$. It is due to increase in household income, increase in automobile production, improvement in road infrastructure and easy availability of car financing at low interest. Year wise excess number of mini buses and auto rickshaws are also shown in the following figure $5 \mathrm{~b}$ and $5 \mathrm{c}$ which depict the irregular pattern in the study area.

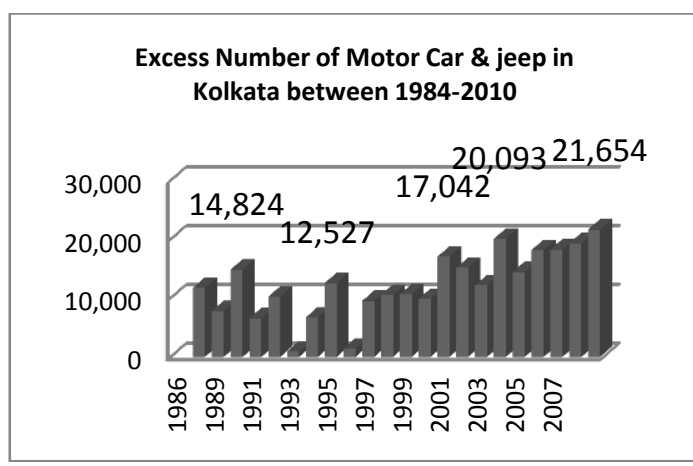

Figure 5a

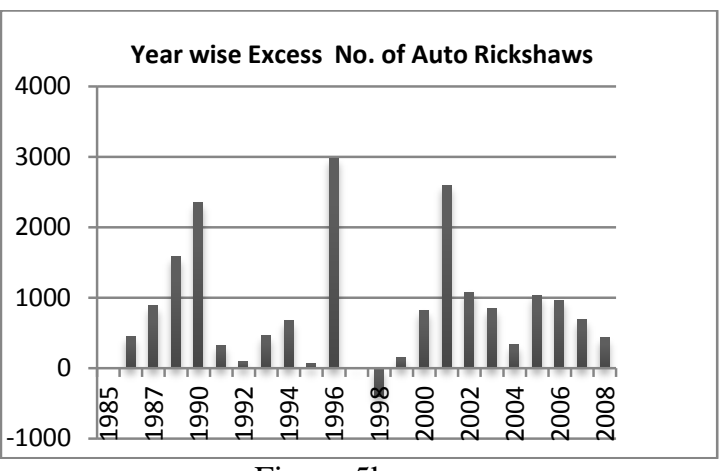

Figure $5 b$ 
Excess no. of Buses and Minibuses in Kolkata year wise 1985-2010

Excess Mini Bus

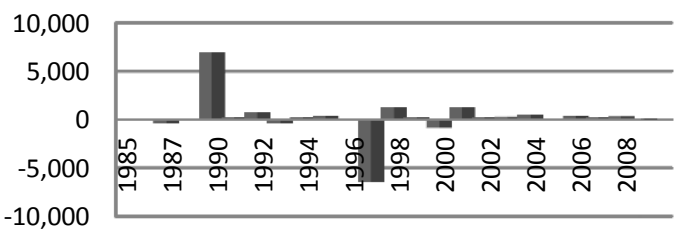

No. of Live Motor Cars \& Motor Cycle in Kolkata ( 1985-2010)

Figure $5 d$

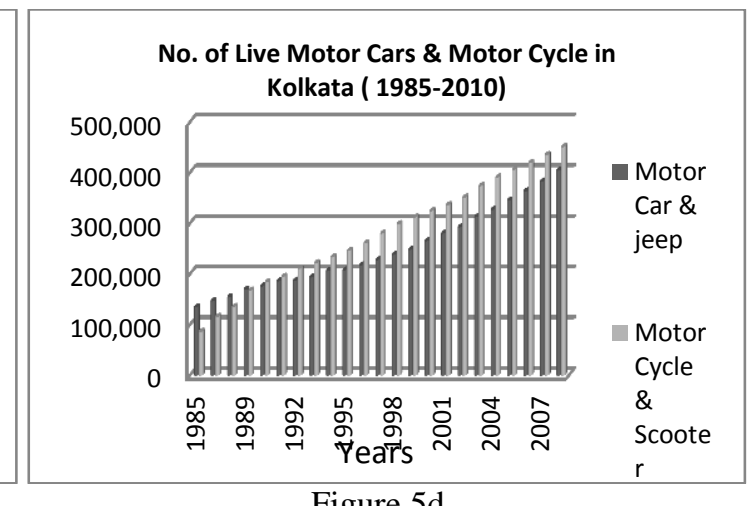

Figure: $5 c$

V. Emissions From Different Vehicle Type

The transport sector is the single largest contributor to air pollution and vehicular pollution in the cities. There is a positive relationship between vehicular explosion and vehicular pollution in the cities. Automobile emission is reportedly responsible for more than half of the air pollution load in Kolkata [3]. Kolkata is the most polluted city in India and also in the world and is around 2.5 times more dangerous than the capital city of Delhi [4]. The major pollutants released as vehicle emissions are, carbon monoxide, nitrogen oxides, photochemical oxidants, air toxics namely benzene, aldehydes, 1-3 butadiene, lead, particulate matter, hydrocarbon, oxides of sulphur and polycyclic aromatic hydrocarbons. While the predominant pollutants in petro/gasoline driven vehicles are hydrocarbons and carbon monoxide, the predominant pollutants from the diesel based vehicles are Oxides of nitrogen and particulates. The emission of carbon monoxide from vehicles contributes nearly $76 \%$ to $90 \%$ of total pollution load and emission of nitrogen oxide contributes $66 \%$ to $74 \%$ of the total pollution load in Kolkata [6].

The transport sector contributes significantly to the emission of Global greenhouse gases resulting in a rise in global temperature and climate change. A troubling aspect of emission from the transport sector is that they are increasing rapidly. With the ongoing increase in population Kolkata, availabilities of cheaper vehicles, and the desire to own private vehicles have a huge implication on ongoing effort towards containment of GHG emissions. The TABLE: 2 shows the emissions of $\mathrm{Co}, \mathrm{HC}, \mathrm{NO}_{2}$ and $\mathrm{SO}_{2}$ from different vehicles which play dominant roles in changing micro climate in a region. Emission of Co and $\mathrm{HC}$ are highest from Car and Jeep followed by Bus ,Goods Vehicle, Two Wheeler, and Auto Richshaw.

Table :2 Emission Factors (grams per km) for Different Transportation Modes

\begin{tabular}{|l|l|l|l|l|l|l|}
\hline Emission Factors & Car \& Jeep & Two Wheeler & Bus \& Mini Bus & Taxi & Goods Vehicle & Auto Rickshaw \\
\hline $\mathbf{( G m} / \mathbf{K g})$ & & & & & & \\
\hline $\mathrm{CO}$ & 40 & 8.3 & 12.7 & 1.1 & 12.7 & 12.24 \\
\hline $\mathrm{HC}$ & 6 & 5.6 & 2.1 & 0.3 & 2.1 & 7.65 \\
\hline $\mathrm{NO}_{2}$ & 3 & 0.1 & 21 & 1.2 & 21 & 0.1 \\
\hline $\mathrm{TSP}$ & 0.3 & 0.5 & 2 & 0.6 & 3 & 0.5 \\
\hline $\mathrm{SO}_{2}$ & 0 & 0.1 & 2.5 & 0.9 & 1.5 & 0.1 \\
\hline Fuel Type & Petrol & Petrol & Diesel & Diesel & Diesel & Petrol \\
\hline Av, Km/ Vehicle & $\mathbf{3 0}$ & $\mathbf{1 5}$ & $\mathbf{2 1 0}$ & $\mathbf{1 8 0}$ & $\mathbf{9 0}$ & $\mathbf{9 0}$ \\
\hline
\end{tabular}

Source: Bento \&Bannerjee (2001), Banerjee\& Das (2001), Bose (1998), Sustaining Calcutta(1996), Agarwal(1996)

$\mathrm{Co}_{2}$ and water vapour are the major exhaust component emitted by engines, after combustion of petroleum-based fuels (gasoline, diesel fuel, natural gas, etc.). $\mathrm{Co}_{2}$ represents more than $99 \%$ by mass of all the gaseous components of exhaust $\left(\mathrm{CO}_{2}, \mathrm{CO}, \mathrm{HC}\right.$, $\mathrm{NOX}$, etc) with catalytic and other exhaust systems, a large part of the carbon monoxide $(\mathrm{CO})$ and hydrocarbons $(\mathrm{HC})$ is oxidized to $\mathrm{CO}_{2}$ and $\mathrm{H}_{2} \mathrm{O} . \mathrm{CO}_{2}$ is considered the predominant form of population emitted from internal combustion engines and also plays a dominant role in changing climate of the city [5]. Nitrogen oxide emissions from vehicles produce a verity of adverse health and environmental effects. Once in the atmosphere, $\mathrm{NO}_{\mathrm{x}}$ emissions react chemically with other pollutants to from tropospheric ozone (the primary component of photochemical smog) and other toxic pollutants. $\mathrm{NO}_{\mathrm{x}}$ emissions are an important precursor to acid rain that may after both terrestrial and aquatic ecosystems. Nitrogen dioxide and airborne nitrate also contribute to pollutant haze, which impairs visibility. 
The most important contributors to worldwide emissions of $\mathrm{NO}_{\mathrm{x}}$ are heavy-duty vehicles and buses, responsible for half the world's emissions of motor vehicle-related $\mathrm{NO}_{\mathrm{x}}$ in spite of a comparatively small share (around 5\%) of the world vehicle population [10].

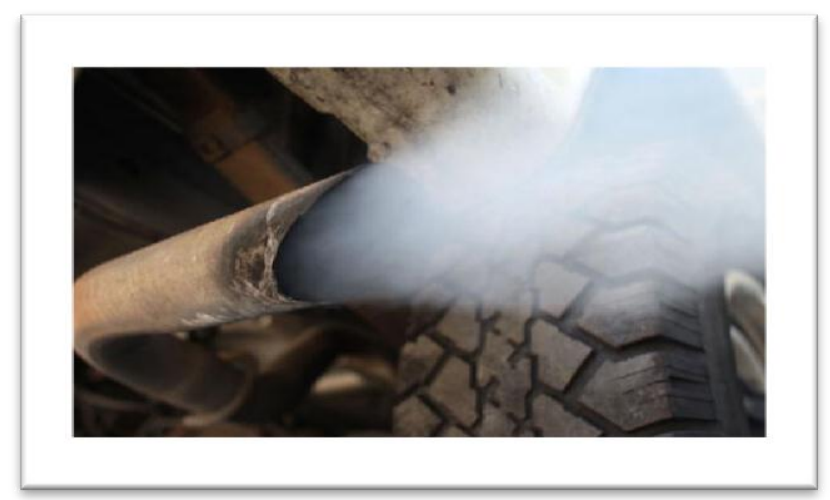

Emission from Vehicles

\section{Role Of Vehicular Pollutionin Climate Change}

The city of Kolkata experiences a very humid and warm summer during the months of April to October with temperature reaching up to $42^{\circ} \mathrm{C}$. During the winter months the temperature drops to about $9.6^{\circ} \mathrm{C}$. The weather in Kolkata is influenced by the sea and has a very tropical type of climate with the summer being hot and humid. The maximum temperature rises during the summer months of May-June up to $24^{\circ} \mathrm{C}-42^{\circ} \mathrm{C}$ and the minimum temperature falls during winter months of December - January up to $8^{\circ} \mathrm{C}-26^{\circ} \mathrm{C}$ on an average. Climate is humid during the summer and exceeding by pleasant in winter. The average rainfall of Kolkata is $1605 \mathrm{~mm}$. Kolkata is located at a point where river Hooghly merges into the sea. In fact the whole region is part of the great Gangetic delta. The weather in Kolkata is influenced by the sea and has a very tropical type of climate with the summer being hot and humid. The temperature seldom crosses the 43 degree Celsius barrier and in winter rarely goes below $8^{\circ} \mathrm{C}$.

\section{1 mean annual minimum and maximum temperature}

To study the relationship between vehicular explosions and climate change, regression analysis has been done for Kolkata. Five regression graphs have been drawn to study the relationship between number of vehicle increase and change in mean minimum or maximum temperature with the help of four parameters (total vehicular population, change in total vehicular population and change in number of personal vehicles, change in mean minimum temperature and maximum temperature) for Kolkata from 1984-2010 .

The graphs( Fig: 6a) show that annual mean minimum temperature is increasing and has a positive trend line with $\mathrm{r}$ value +0.52 in Kolkata city So, it may be said that Kolkata is becoming warmer in the recent decade and the role of commercial vehicles as well as personal vehicles is very much significant in changing mean minimum temperature. Mean minimum temperature has increased from $21.8^{\circ} \mathrm{C}$ (1984) to $23^{\circ} \mathrm{C}$ (2010), increased at $1.2^{\circ} \mathrm{C}$ in the twenty five years at Kolkata. Even the relationship between the personal vehicles and change in total vehicles yearly with that of mean minimum temperature also suggest that there is very strong positive correlation between them. So, there is warming signs in night temperature in Kolkata. The present work has revealed that majority of the tendencies witnessed significant increase in mean minimum temperature, but with inconsistent rates. Although a steeper significant increase in Mean Minimum temperature has been observed in Kolkata but there is significant decrease in mean maximum temperature (figure 6b,c and d). The relationship between two variables i.e change in the number of total vehicles and mean maximum temperature shows a negative relationship in the study period (Fig: 6e). The slope of the trend line is not only negative but it is not also steep (r value .014). So the relationship is not very much strong as mean minimum temperature. Still it may be said that with the increase of personal or total vehicles mean maximum temperature is not increasing in Kolkata. 


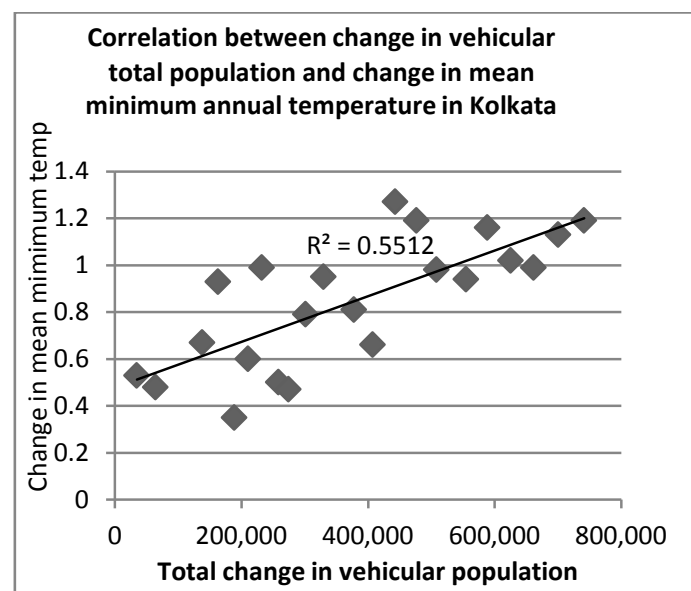

Figure: 6a

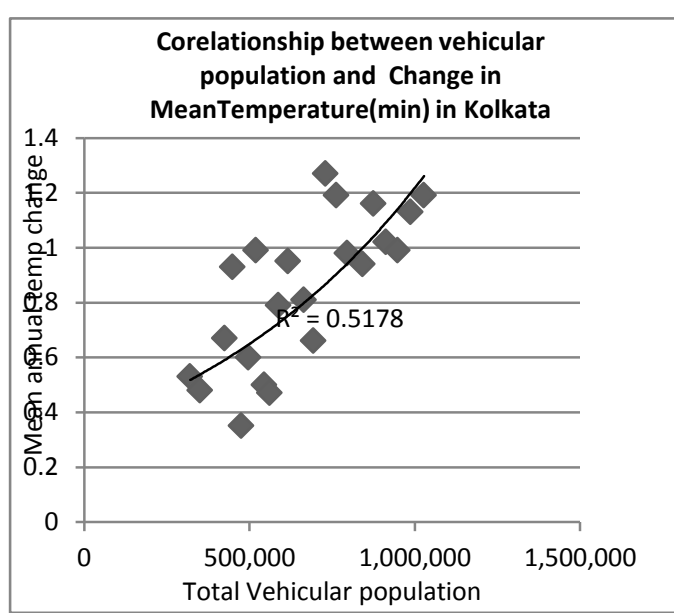

Figure: $6 c$

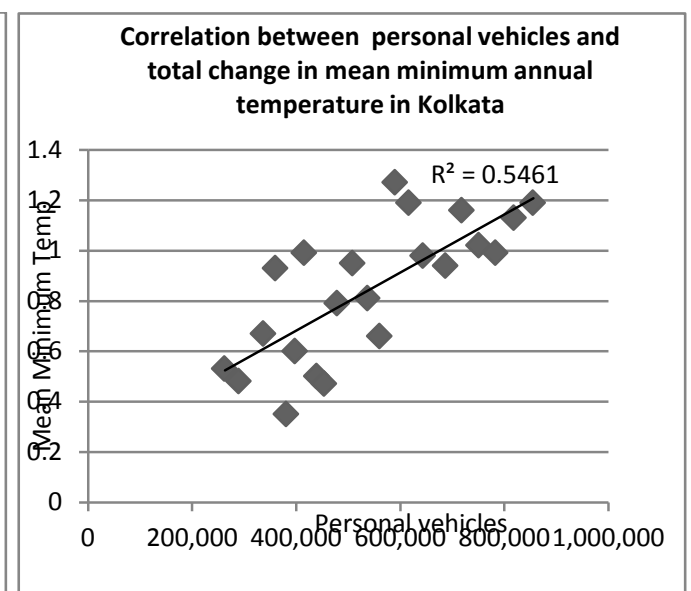

Figure: $6 b$

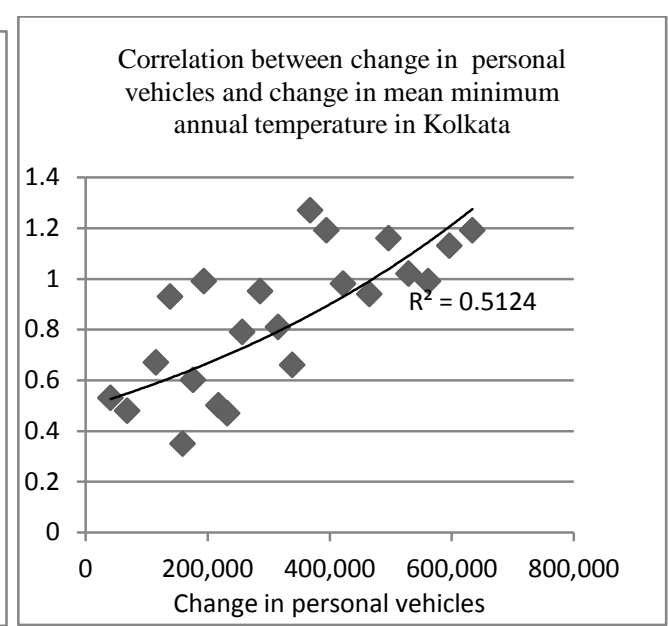

Figure : $6 \mathrm{~d}$

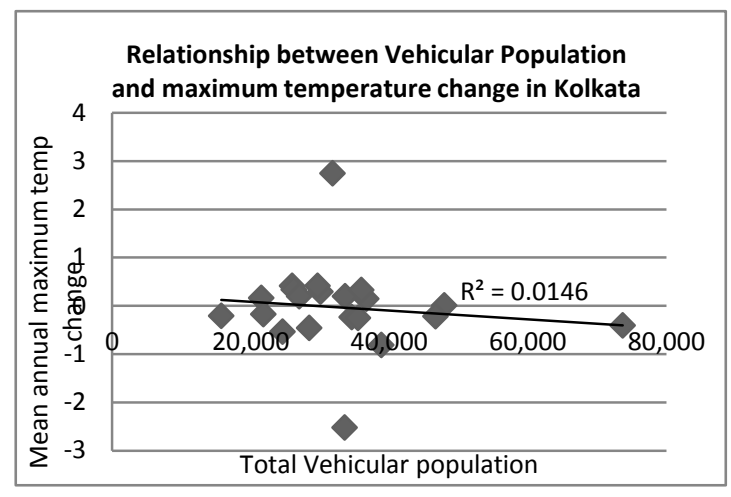

Figure:6e

\section{2 seasonal changes}

During summer season Kolkata has positive and increasing trend of minimum temperature. So, it explains that mean minimum temperature is increasing with increase in total vehicles. In Kolkata, all years have positive values with respect to 1984 base year only with exception to $1990(-0.3)$ and $1993(-0.5)$. The average mean minimum temperature is $22.6^{\circ} \mathrm{c}$. It was $21.8^{\circ} \mathrm{c}$ in 1984 and in 2007 it was $23.2^{\circ} \mathrm{c}$ (Fig. $7 \mathrm{~b}$ ). So the difference between 1984 and 2007 is $1.4^{\circ} \mathrm{c}$. So, it is observed that mean minimum temperature is increasing with positive trend line( $\mathrm{r}$ value 0.23 ). Summer evening and nights have shown warming signs.

Summer is followed by the season of rains, monsoon. In monsoon the mean minimum temperature showed significant decrease at Kolkata. In 1984 , the mean minimum was $22.7^{\circ} \mathrm{C}$ and became $23.4^{\circ} \mathrm{c}$ in 2010 , so significant increase rise at $0.7^{\circ} \mathrm{c}$. But overall 2000 onwards a decreasing trend was observed. So the regression 
graph shows there is not much change in mean minimum temperature with increase of vehicles in monsoon (Fig. 7c).

October and November are considered as post monsoon season. This is the time when rain ceases, sky becomes clearer and temperature rises. Under these circumstances if the temperature continues to raise it will lead to lowering of comfort levels in cities. This has what exactly happened in the post monsoon season. Kolkata has registered rise in post monsoon mean minimum temperature. A significant positive trend with $r$ value 0.03 and a sharp increase of mean minimum temperature are observed at Kolkata (Fig: $7 \mathrm{~d}$ ). There is positive correlation between change in vehicular population and change in mean minimum temperature in the study area. So, mean minimum temperature in Kolkata is increasing with increase of vehicles in Post monsoon period.

Kolkata had pleasant period of autumn or post monsoon season after three months of monsoon in mid 80 s' with low minimum temperature but rapid urbanization, changing land use, rampant filling of open space and wetlands, air pollution and vehicular explosion all have contributed very much in increasing mean minimum temperature and lowering the comfort level. The graph for post monsoon period also proves a very strong relationship between changes in vehicular population and means minimum temperature in Kolkata.

During winter a rise in mean minimum temperature and a positive trend line have been observed in Kolkata. The relationship is more significant in Kolkata. In Kolkata, the average mean minimum temperature was $15.3^{\circ} \mathrm{C}$ in winter and 1997 onwards all the years had above the average temperature. Kolkata is becoming warmer in winter period and mainly due to vehicular explosion (Fig: 7a).

In general it can be said that most of the tendencies showed increase in temperature with increase in vehicular population. The effect of vehicular explosion is usually reflected in the increase in night temperature represented by mean minimum temperature. The present work revealed that majority of the tendencies witnessed significant increase in mean minimum temperature, but with inconsistent rates. Highest increase was registered at Kolkata in summer and lowest significant increase was recorded Monsoon period. From these results it can be inferred that though vehicular explosion has contributed to warming, it is not the case always especially in monsoon period.

\section{Seasonal Changes of Mean Minimum Temperatures with increasing vehicles Kolkata (1984-2010)}

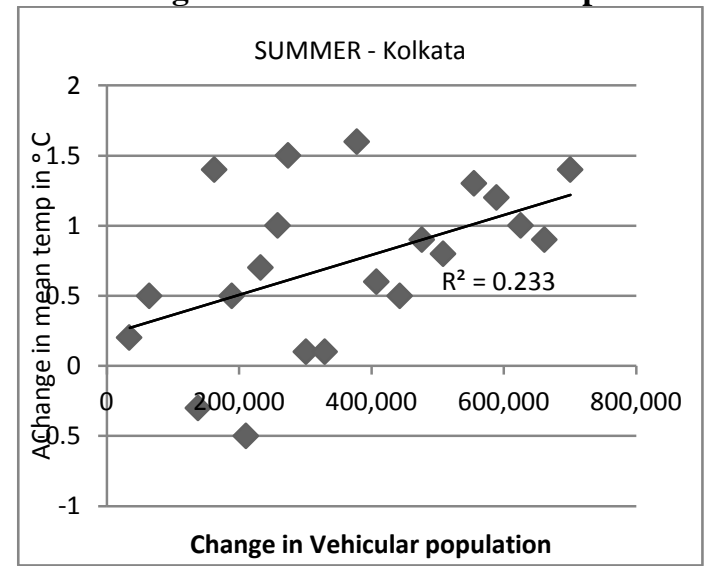

Figure: $7 \mathrm{a}$

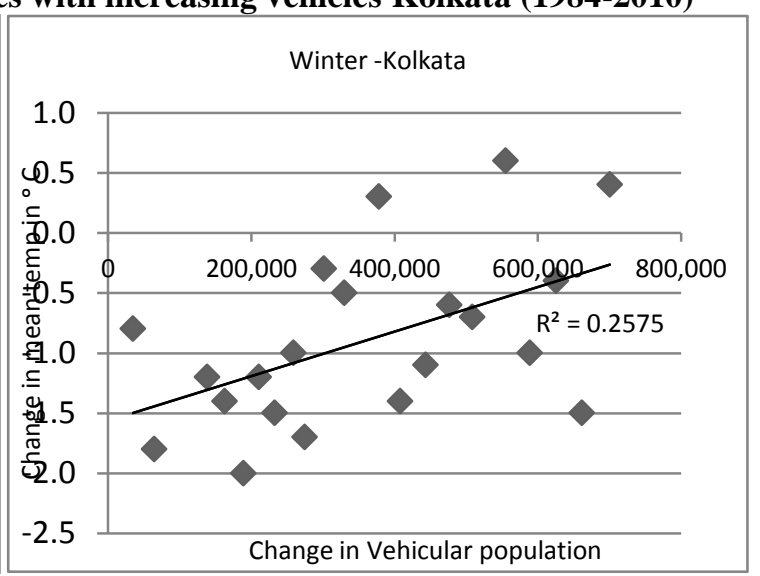

Figure: $7 b$

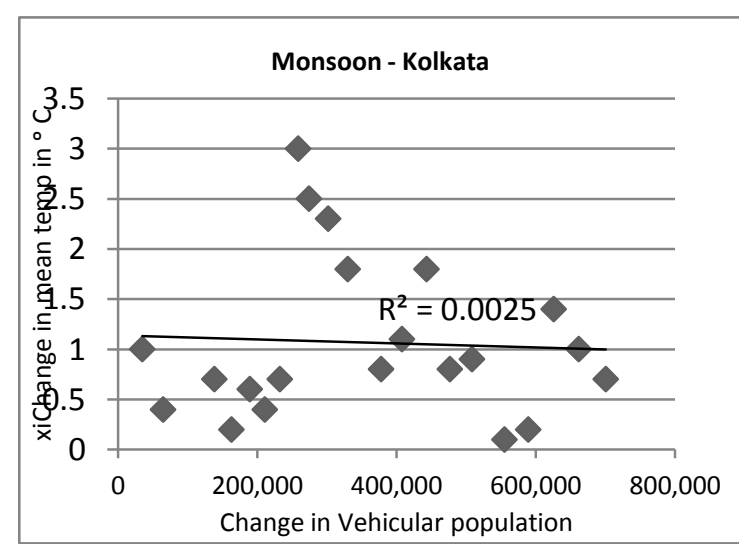

Figure: $7 \mathrm{c}$

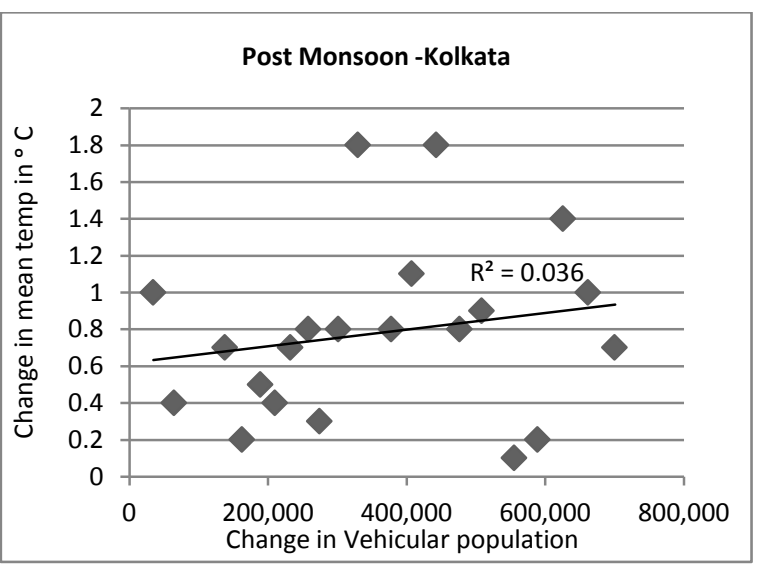

Figure: $7 d$ 
So, pollution control and reduction of emission of carbon monoxide and carbon dioxide gases into the atmosphere from road transport sector and climate change in India is a tough challenge [5]. So, it may be said that Kolkata is becoming warmer in the recent decade and the role of commercial vehicles as well as personal vehicles is very much significant in changing mean minimum temperature.

\section{Conclusions}

With rapid urbanization, the increased travel demand has resulted in rapid growth in the number of motor vehicles specially two wheelers and personalized cars in Kolkata. Kolkata has the highest in vehicular density in India per $\mathrm{km}$ among all mega cities as in India as the road space is very insufficient i.e. $6 \%$ in urban land use scenario in Kolkata [9]. The exponential growth of personal vehicles are solely responsible for air and as well as vehicular pollution in Kolkata city. So, the proliferation of growth of transport has resulted in changes in air temperature in Kolkata. The relationship between two variables (total vehicles and changes in mean and maximum growth of temperature with base year -1984) has been shown with the help of regression analysis. In general it can be said that the most of the tendencies showed increase in temperature with increase in vehicular population or changes in personal vehicles. The effect of vehicular explosion is usually reflected in the increase in night temperatures represented by mean minimum temperature. The present work revealed that majority of the tendencies witnessed significant increase in mean minimum temperature, but with inconsistent rates.

The regression results suggest a positive and significant relationship between growth of personal vehicles and change in mean annual temperature and the trend line has a positive " $r$ value of +0.52 ". Understandably, the emissions of carbon monoxide, lead, sulphur oxides, nitrogen oxides, etc. from vehicles contribute to this increase. Highest increase was registered at Kolkata in summer and lowest significant increase was recorded in monsoon period. From these results it can be inferred that though vehicular explosion have contributed to warming in all seasons - summer winter and post monsoon in only with exception in monsoon periods. So, it may be said that Kolkata is becoming warmer in the recent decade and the role of commercial vehicles as well as personal vehicles is very much significant in changing mean minimum temperature. So, there is urgent need to combat this alarming situation with heavy hands. Reduce vehicle use and traffic reform can be a bigger and more immediate remedy for urban air pollution. The major thrust of urban transport policy should include integrated planning, improvement of public mass transport system i.e. buses; "point to point connectivity" transport system. Moreover, calculation of carbon emission per car in the city and calculation of total emission of carbon in the atmosphere will be helpful to combat against pollution and climate change [8].

Priority should also be given for the design and developments of modern and sophisticated bus transport systems to increase their use in Kolkata. Buses are the safest modes of transport in densely populated city as they cater $60 \%$ of total passenger load on roads [9]. This will be an important step towards a sustainable public transport system. There should be introduction of safe entry and exit modus operandi for bus passengers. This will require all buses to be fitted with closing doors, low floors and properly designed bus stops [7]. In Kolkata number of buses has been declined due to phasing out older buses and induction of new buses.

The research has shown that Kolkata is more vulnerable city with respect to vehicular pollution, air pollution and also change of mean minimum temperature in summer, winter and post monsoon period. So, in Kolkata the government should promote use of cleaner technology and alternate fuel for personal vehicles (e.g. $\mathrm{CNG}$ ) to reduce the vehicular pollution as well as to fight against changing climate [10]. The use of CNG will reduce the petrol demand as well as $\mathrm{CO}$ emission in future. Therefore strengthening the public transport system, especially the railroad and promoting cleaner fuel and improved engine technologies can reduce the emission of green house gases from transport and also can reduce the harmful effects of increasing mean minimum and maximum temperature [5].

There is also considerable progress in reducing emissions for new cars, but this progress is undermined by the increased use of cars, particularly old and inefficient models, accompanied by the trend to move to bigger cars such as sport utility vehicles. The easiest solution is to promote the use of smaller, low emission vehicles by changing purchasing behaviour. Manufacturers need to be encouraged to continually develop ultra-efficient engines such as those seen in small cars [5].

The abnormal increases in urban population, haphazard urban growth, and growth of personal vehicles have caused unbridled problems of air and vehicular pollution in Kolkata in varying degrees. The levels of these pollutions have risen to alarming proportions. It is therefore urgently required to develop a safe and eco-friendly transport environment. Adequate measures must be taken in terms of technological modifications in vehicles, introduction of new technologies fuel integrated land-use transportation planning, properly planned transport system management, public and non-motorized transport etc. to cater to the need of people for a sustainable transport environment. 


\section{Acknowledgements}

The author wish to express her gratitude towards India Meterological Department-Pune for providing the climatic data, Transport Department Govt. of West Bengal and University Grants Commission for funding this project.

\section{References}

[1] Chapmar. L, Transport and Climate Change: a review. Journal of Transport Geography, 15, 2007, 354-367.

[2] Sharma. D., Tomar, S, Mainstreaming Climate Change adaptation in Indian cities. Environment and Urbanization,22(2), 2010, 451-466

[3] Ghose. K.M, Air Pollution in the city of Kolkata: Health Effects Due to Chronic Exposure, Environmental Quality Management,19(2),2009,53-70

[4] Ghosh. A.R., Air Pollution and Health in Calcutta: A Geographical Analysis, Geographical Review of India, 62, 1995, 370-378.

[5] Das.D, Sharfouddin. A , Dutta.S, Personal Vehicles in Delhi : Petrol Demands and Carbon emission, International Journal of Sustainable Transportation, Volume:3, 2009, 122-137

[6] Status of the vehicular pollution control programme in india, Published by Central Pollution Control Board, Ministry of Environment \& Forest.

[7] Rupa Kumar, K. \& Hingane, L.S., Long-term variations of surface air temperature at major industrial cities of India, Climate Change, 13,1988,.287-307.

[8] Hickman, R., Ashiru, O., Banister, D.,Transport and climate change: Simulating the options for Carbon reduction in London,Transport Policy, 17, 2010, 110-25

[9] Annual Report, Published by Transport Department Government Of West Bengal, 2009-2010,Kolkata.

[10] Fuglesvedt, J.S., Shine, K.P., Berntsen T., Cook, J., Lere, D.S., Sterke, A. Skeie, R.B., Velders, G. J.M., Waitz, I.A. Transport impact on atmosphere and climate: Metrics. Atmospheric Environment, 44, 2010, 4648-4677. 